\title{
Diaphragm Muscle Thinning in Subjects Receiving Mechanical Ventilation and Its Effect on Extubation
}

\author{
Horiana B Grosu MD, David E Ost MD MPH, Young Im Lee MD, Juhee Song PhD, \\ Liang Li PhD, Edward Eden MD, and Keith Rose MD
}

\begin{abstract}
BACKGROUND: Diaphragm muscle weakness and atrophy are consequences of prolonged mechanical ventilation. Our purpose was to determine whether thickness of the diaphragm (TDI) changes over time after intubation and whether the degree of change affects clinical outcome. METHODS: For this prospective, longitudinal observational study, we identified subjects who required mechanical ventilation and measured their TDI by ultrasonography. TDI was measured at baseline and repeated $72 \mathrm{~h}$ later and then weekly until the subject was either liberated from mechanical ventilation, was referred for tracheostomy, or died. The analysis was designed to determine whether baseline TDI and change in TDI affect extubation outcome. RESULTS: Of the 57 subjects who underwent both diaphragm measurements at $72 \mathrm{~h}, 16$ died, 33 were extubated, and 8 underwent tracheostomy. Only 14 subjects received mechanical ventilation for 1 week, and 2 subjects received mechanical ventilation for 2 and 3 weeks. Females had significantly thinner baseline TDI $(P=.008)$. At $72 \mathrm{~h}$, TDI had decreased in $84 \%$ of subjects. We found no significant association between the rate of thinning and sex $(P=.68)$, diagnosis of COPD $(P=.36)$, current smoking $(P=.85)$, or pleural effusion $(P=.83)$. Lower baseline TDI was associated with higher likelihood of extubation: $12.5 \%$ higher for every $0.01-\mathrm{cm}$ decrease in TDI (hazard ratio 0.875 , 95\% CI 0.80-0.96, $P=.003$ ). For every $0.01-\mathrm{cm}$ decrease in TDI at $72 \mathrm{~h}$, the likelihood of extubation increased by $17 \%$ (hazard ratio $0.83,95 \%$ CI $0.70-0.99, P=.041$ ). CONCLUSIONS: Although most of the subjects showed evidence of diaphragm thinning, we were unable to find a correlation with outcome of extubation failure. In fact, the thinner the diaphragm at baseline and the greater the extent of diaphragm thinning at $72 \mathrm{~h}$, the greater the likelihood of extubation. Thickening ratio or other measurement may be a more reliable indicator of diaphragm dysfunction and should be explored. Key words: diaphragm thinning; ultrasound; mechanical ventilation. [Respir Care 2017;62(7):904-911. (C 2017 Daedalus Enterprises]
\end{abstract}

\section{Introduction}

Mechanical ventilation is one of the most frequently used critical care technologies; approximately $10-15 \%$ of

Drs Grosu and Ost are affiliated with the Department of Pulmonary Medicine and Drs Song and Li are affiliated with the Department of Biostatistics, University of Texas MD Anderson Cancer Center, Houston, Texas. Drs Lee, Eden, and Rose are affiliated with the Division of Pulmonary, Critical Care, and Sleep Medicine, Mount Sinai West, New York, New York.

This work was supported by National Cancer Institute, National Institutes of Health, Grant P30CA016672, which supports the Biostatistics core facility at the University of Texas MD Anderson Cancer Center. The authors have disclosed no conflicts of interest. critically ill patients will require prolonged mechanical ventilation and an elective tracheostomy. ${ }^{1-4}$ While ventilated, patients may develop critical illness that leads to substantial skeletal muscle weakness, disability, and poor health-related quality of life. ${ }^{5,6}$

A rapidly accumulating body of evidence suggests that mechanical ventilation, with its associated diaphragm mus-

\footnotetext{
Correspondence: Horiana B Grosu MD, Department of Pulmonary Medicine, Unit 1462, University of Texas MD Anderson Cancer Center, 1515 Holcombe Boulevard, Houston, TX 77030. E-mail: bogdana_14@yahoo.com.
}

DOI: $10.4187 /$ respcare. 05370 
cle inactivity and unloading, is an important cause of diaphragm dysfunction secondary to diaphragmatic atrophy. This dysfunction may prolong the duration of mechanical ventilation and hospital stay. ${ }^{7-9}$ Animal and human studies have defined ventilator-induced diaphragm dysfunction as the loss of diaphragmatic force-generating capacity specifically related to the use of mechanical ventilation. ${ }^{10-13}$ Ventilator-induced diaphragm dysfunction results from oxidative injury, elevated proteolysis, and atrophy of the diaphragm fibers. ${ }^{12}$ The major clinical implication of ventilator-induced diaphragm dysfunction is that, even after relatively short periods of mechanical ventilation, substantial diaphragmatic weakness and wasting may occur, with consequent adverse effects on the process of weaning from mechanical ventilation. ${ }^{4}$

In a prior study, ${ }^{14}$ we showed that ultrasonography can provide an accurate, noninvasive measurement of diaphragm thickness (TDI). Daily measurement of TDI in subjects receiving mechanical ventilation revealed that diaphragm muscle starts to thin within $48 \mathrm{~h}$ after the initiation of mechanical ventilation. In view of the small sample size in that study, however, we were unable to assess whether the thinning correlated with clinical outcomes such as extubation. ${ }^{14}$

In the current study, we hypothesized that intubated subjects would develop diaphragmatic thinning by $72 \mathrm{~h}$ after the initiation of mechanical ventilation. Hence, the main outcome was to quantify changes in TDI at $72 \mathrm{~h}$ from the baseline TDI. The secondary outcome was to determine how TDI affects the time to extubation compared with subjects who undergo tracheostomy or die.

\section{Methods}

We performed a prospective, longitudinal observational study to measure TDI using ultrasound shortly after endotracheal intubation and the initiation of mechanical ventilation and analyzed their relationship with extubation outcome. Approval was obtained from the institutional ethics review boards of both Mount Sinai St. Luke's and Mount Sinai Roosevelt hospitals (protocol 09-222) and from Institutional Review Board Committee 4 of MD Anderson Cancer Center (protocol 14-1053). Patients were recruited from the emergency department of Mount Sinai St. Luke's and Mount Sinai West hospitals during the period from October 2010 to January 2011.

\section{Study Subjects}

Subjects age $\geq 18$ y with respiratory failure requiring mechanical ventilation who gave written consent to participate in this study were included. We excluded patients who already had a tracheostomy and patients who were being re-intubated within $72 \mathrm{~h}$ of a prior extubation. Base-

\section{QUICK LOOK}

\section{Current knowledge}

Patients receiving mechanical ventilation show evidence of thinning of the diaphragm on serial ultrasound measurements. Although it is clear that thinning of the diaphragm occurs over time in mechanically ventilated patients, no studies have shown a correlation between the degree of diaphragmatic thinning and diaphragmatic strength; nor have they shown a correlation between diaphragm atrophy and time to extubation.

\section{What this paper contributes to our knowledge}

Our results support the hypothesis that patients receiving mechanical ventilation begin to develop diaphragm thinning soon after intubation. However, although most of the subjects showed evidence of diaphragm thinning, we were unable to find a correlation with outcome of extubation.

line clinical and demographic information was extracted from the subject's medical record.

Successful extubation was defined as extubation without re-intubation within the following $72 \mathrm{~h}$. Extubation failure was defined as death or tracheostomy with a need for continuous ventilator support. All subjects underwent daily assessment for weaning and underwent a weaning trial based on a standardized weaning protocol.

\section{Diaphragm Thickness Measurement}

Diaphragm muscle thickness was measured using a standardized technique described previously by Cohn et al ${ }^{15}$ and also in our previous paper. ${ }^{14}$ The diaphragm was imaged by using the M-Turbo ultrasound system (SonoSite, Bothell, Washington) with a $7.5-10.0-\mathrm{mHz}$ transducer probe in 2-dimensional B-mode. Following subject enrollment, the baseline TDI was measured at the right hemidiaphragm within $24 \mathrm{~h}$ after intubation and initiation of mechanical ventilation. The measurement was repeated $72 \mathrm{~h}$ later and then weekly until the subject either was liberated from mechanical ventilation, was referred for tracheostomy, or died.

Images were obtained at end expiration, which correlates with functional residual capacity. By measuring TDI at end expiration (functional residual capacity) when the diaphragm was unloaded, we were able to measure TDI serially without regard to the level of ventilatory support the patient was receiving. We obtained 3 consecutive images to establish the reproducibility of our measurements. During ultrasound examination, we observed real-time 
graphics of air flow and airway pressure at the point of end expiration. ${ }^{14}$ Images were edited only for the removal of subject information and were interpreted by a separate, blinded interpreter. For standardization, the image with the greatest thickness was used as the final measurement. Measurements are given in $\mathrm{cm}$. We took one measurement on each day for each subject.

The rate of thinning was calculated as baseline TDI minus second TDI measurement (TDI2) divided by the time interval between the 2 measurements. For subjects with $>2$ measurements, the rate of thinning was also assessed as baseline TDI minus the last TDI measurement divided by the time interval between the 2 measurements.

\section{Statistical Methods}

Subject demographics and baseline clinical characteristics were summarized with descriptive statistics according to extubation success or failure (ie, death or tracheostomy). The Kruskal-Wallis test or 2-sample $t$ test was used to analyze continuous variables, and the chi-square test or Fisher exact test was used to analyze categorical variables. Analysis-of-covariance models were fitted, including final outcome (extubation vs death or tracheostomy) and subject sex as fixed effects, baseline TDI as a covariate, and change in TDI from the baseline to the second measurement as the response variable. Only the first 2 TDI measurements were used for the analysis-ofcovariance models.

A Cox multivariate proportional hazards regression model with time to extubation as the outcome variable was performed. The Cox model was fitted, including baseline TDI measurement and the change from baseline to TDI2 as predictors. Subjects who were not successfully extubated were censored at the time of death or tracheostomy. An extended Cox model considering diaphragm thickness measurement as a time-dependent covariate was fitted as well. $P$ values were determined; all tests were 2 -sided. All statistical analyses were performed in SAS 9.4 (SAS Institute, Cary, North Carolina). $P$ values of $<.05$ were considered to be significant.

\section{Results}

Of the 185 eligible patients identified during the study period, 79 consented and were enrolled in the study. Each of these subjects underwent the baseline diaphragm measurement, but only 57 underwent the second diaphragm measurement $72 \mathrm{~h}$ later and thus were evaluable. Of these 57 subjects, 33 were extubated, 8 underwent tracheostomy and 16 died. The median time to death was $8 \mathrm{~d}$ (range 3-13 d), and the median time to extubation was $6 \mathrm{~d}$ (range 2-29d). The mean time to tracheostomy was $11.5 \mathrm{~d}$ (range 7-24 d). There were 10 subjects who were

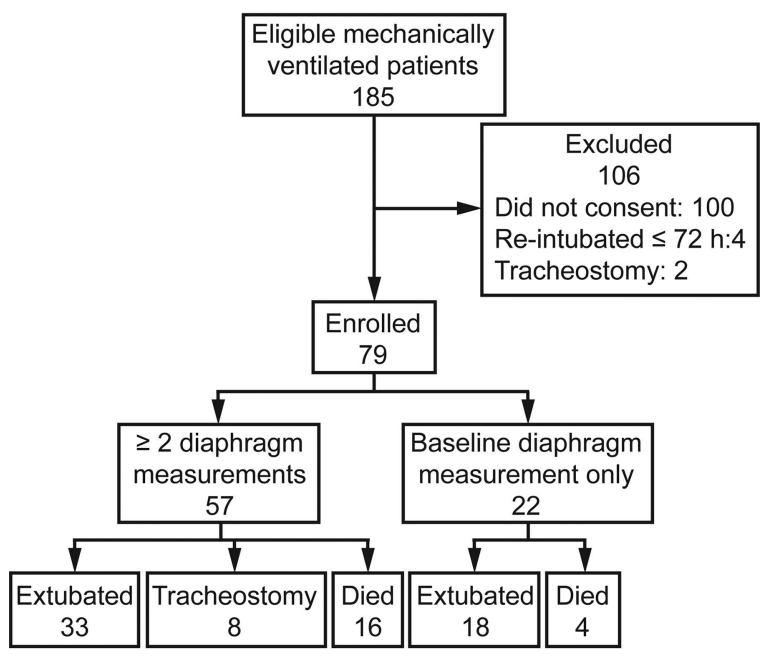

Fig. 1. Flow chart.

intubated for airway protection, and of these 10, 6 were extubated, 3 died, and 1 underwent tracheostomy. The subject who underwent tracheostomy did not undergo tracheostomy due to neurological issues but due to failure to wean. A flow chart of patients eligible for and included in the study is shown in Figure 1. All subjects in our study were sedated to achieve a Richmond Agitation-Sedation Scale score of -2 or higher. Subject demographics and clinical characteristics are summarized according to final outcome in Table 1.

\section{Diaphragm Thickness at Baseline}

For this analysis, we included all 79 subjects who underwent the baseline diaphragm measurement. The mean baseline diaphragm thickness was $0.23 \pm 0.06 \mathrm{~cm}$. Females had significantly thinner diaphragms at baseline than males $(P=.001)$. Subjects without COPD had thinner diaphragms at baseline than those with COPD $(P=.034)$, and those without pleural effusion had thinner diaphragms at baseline than those with pleural effusion $(P=.045)$. We found no association between baseline TDI and smoking history $(P=.90)$ (Table 2$)$. No significant linear association between body mass index and baseline TDI was observed (Pearson correlation coefficient $=0.09, P=.43$ ).

\section{Change in Diaphragm Thickness}

For this analysis, we included the 57 subjects who had $\geq 2$ measurements performed. At the second measurement, $72 \mathrm{~h}$ after the baseline measurement, diaphragm thickness had decreased in 48 (84\%) of the 57 subjects. Diaphragm thickness remained unchanged in 8 subjects $(14 \%)$ and increased in $1(2 \%)$. 
Table 1. Descriptive Statistics of Subject and Clinical Characteristics by Extubation Outcome

\begin{tabular}{|c|c|c|c|}
\hline Covariate & $\begin{array}{l}\text { Death or } \\
\text { Tracheostomy } \\
(n=24)\end{array}$ & $\begin{array}{l}\text { Extubated } \\
(n=33)\end{array}$ & $P$ \\
\hline Age, mean \pm SD y & $65.7 \pm 16.7$ & $60.0 \pm 19.8$ & .25 \\
\hline $\mathrm{BMI}$, mean $\pm \mathrm{SD} \mathrm{kg} / \mathrm{m}^{2}$ & $28.4 \pm 8.9$ & $25.5 \pm 7.7$ & .20 \\
\hline Sex, $n(\%)$ & & & .25 \\
\hline Female & $8(33.3)$ & $16(48.5)$ & \\
\hline Male & $16(66.7)$ & $17(51.5)$ & \\
\hline Race, $n(\%)$ & & & .90 \\
\hline African-American & $8(33.3)$ & $8(24.2)$ & \\
\hline Asian & $0(0)$ & $1(3)$ & \\
\hline Hispanic or Latino & $5(20.8)$ & $8(24.2)$ & \\
\hline White & $11(45.8)$ & $16(48.5)$ & \\
\hline Malignancy, $n(\%)$ & & & $>.99$ \\
\hline No & $21(87.5)$ & $29(87.9)$ & \\
\hline Yes & $3(12.5)$ & $4(12.1)$ & \\
\hline COPD/emphysema, $n(\%)$ & & & $>.99$ \\
\hline No & $21(87.5)$ & $28(84.8)$ & \\
\hline Yes & $3(12.5)$ & $5(15.2)$ & \\
\hline Liver disease, $n(\%)$ & & & .45 \\
\hline No & $22(91.7)$ & $27(81.8)$ & \\
\hline Yes & $2(8.3)$ & $6(18.2)$ & \\
\hline Congestive heart failure, $n(\%)$ & & & .49 \\
\hline No & $17(70.8)$ & $26(78.8)$ & \\
\hline Yes & $7(29.2)$ & $7(21.2)$ & \\
\hline Coronary artery disease, $n(\%)$ & & & .49 \\
\hline No & $17(70.8)$ & $26(78.8)$ & \\
\hline Yes & $7(29.2)$ & $7(21.2)$ & \\
\hline Neuromuscular disease, $n(\%)$ & & & $>.99$ \\
\hline No & $23(95.8)$ & $31(93.9)$ & \\
\hline Yes & $1(4.2)$ & $2(6.1)$ & \\
\hline Connective tissue disease, $n(\%)$ & & & $>.99$ \\
\hline No & $24(100)$ & $32(97)$ & \\
\hline Yes & $0(0)$ & $1(3)$ & \\
\hline $\mathrm{HIV}, n(\%)$ & & & .23 \\
\hline No & $20(83.3)$ & $31(93.9)$ & \\
\hline Yes & $4(16.7)$ & $2(6.1)$ & \\
\hline Smoking history, $n(\%)$ & & & .45 \\
\hline Current & $2(8.3)$ & $6(18.2)$ & \\
\hline Prior/never & $22(91.7)$ & $27(81.8)$ & \\
\hline Substance abuse, $n(\%)$ & & & .22 \\
\hline No & $23(95.8)$ & $27(81.8)$ & \\
\hline Yes & $1(4.2)$ & $6(18.2)$ & \\
\hline Type of respiratory failure, $n(\%)$ & & & .84 \\
\hline Airway protection & $4(16.7)$ & $6(18.2)$ & \\
\hline Hypercapnic (type II) & $1(4.2)$ & $1(3)$ & \\
\hline Hypoxic (type I) & $13(54.2)$ & $21(63.6)$ & \\
\hline Mixed & $6(25)$ & $5(15.2)$ & \\
\hline $\begin{array}{l}\text { Mode of mechanical ventilation, } \\
\quad n(\%)\end{array}$ & & & $>.99$ \\
\hline APRV & $1(4.2)$ & $2(6.1)$ & \\
\hline VC/PRVC & $23(95.8)$ & $31(93.9)$ & \\
\hline Chest radiography finding, $n(\%)$ & & & .87 \\
\hline Diffuse infiltrate & $10(41.7)$ & $16(48.5)$ & \\
\hline Lobar/sublobar infiltrate & $7(29.2)$ & $8(24.2)$ & \\
\hline Normal & $7(29.2)$ & $9(27.3)$ & \\
\hline Pleural effusion, $n(\%)$ & & & .50 \\
\hline No & $18(75)$ & $22(66.7)$ & \\
\hline Yes & $6(25)$ & $11(33.3)$ & \\
\hline
\end{tabular}

Table 1. Continued

\begin{tabular}{|c|c|c|c|}
\hline Covariate & $\begin{array}{c}\text { Death or } \\
\text { Tracheostomy } \\
(n=24)\end{array}$ & $\begin{array}{l}\text { Extubated } \\
(n=33)\end{array}$ & $P$ \\
\hline Sepsis/septic shock, $n(\%)$ & & & .7 \\
\hline No & $15(62.5)$ & $22(66.7)$ & \\
\hline Yes & $9(37.5)$ & $11(33.3)$ & \\
\hline $\begin{array}{l}\text { Multiple-organ-system failure, } \\
n(\%)\end{array}$ & & & $>.99$ \\
\hline No & $21(87.5)$ & $29(87.9)$ & \\
\hline Yes & $3(12.5)$ & $4(12.1)$ & \\
\hline ARDS, $n(\%)$ & & & $>.99$ \\
\hline No & $19(79.2)$ & $25(75.8)$ & \\
\hline Yes & $5(20.8)$ & $8(24.2)$ & \\
\hline Corticosteroid use, $n(\%)$ & & & .38 \\
\hline No & $23(95.8)$ & $28(84.8)$ & \\
\hline Yes & $1(4.2)$ & $5(15.2)$ & \\
\hline Antibiotic use, $n(\%)$ & & & .12 \\
\hline No & $1(4.2)$ & $7(21.2)$ & \\
\hline Yes & $23(95.8)$ & $26(78.8)$ & \\
\hline Pressor use, $n(\%)$ & & &.$\varepsilon$ \\
\hline No & $17(70.8)$ & $24(72.7)$ & \\
\hline Yes & $7(29.2)$ & $9(27.3)$ & \\
\hline Sedation, $n(\%)$ & & & . \\
\hline No & $1(4.2)$ & $0(0)$ & \\
\hline Yes & $23(95.8)$ & $33(100)$ & \\
\hline Neuromuscular block, $n(\%)$ & & & .4 \\
\hline No & $23(95.8)$ & $33(100)$ & \\
\hline Yes & $1(4.2)$ & $0(0)$ & \\
\hline APACHE II score, mean \pm SD & $23.25 \pm 9.9$ & $20.76 \pm 9.6$ & .34 \\
\hline $\mathrm{V}_{\mathrm{T}}$, median (IQR) $\mathrm{mL}$ & $450(400-500)$ & $400(400-450)$ & .14 \\
\hline $\mathrm{V}_{\mathrm{T}} / \mathrm{IBW}$, mean $\pm \mathrm{SD} \mathrm{mL} / \mathrm{kg}$ & $7.06 \pm 1.59$ & $6.82 \pm 1.24$ & .55 \\
\hline $\begin{array}{l}\text { PEEP for VC/PRVC, median } \\
\text { (IQR) } \mathrm{cm} \mathrm{H} \mathrm{H}_{2} \mathrm{O}\end{array}$ & $5(5-5)$ & $5(5-5)$ & .83 \\
\hline \multicolumn{4}{|l|}{ 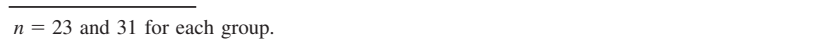 } \\
\hline \multicolumn{4}{|l|}{$\mathrm{BMI}=$ body mass index } \\
\hline \multicolumn{4}{|l|}{$\mathrm{APRV}=$ airway pressure release ventilation } \\
\hline \multicolumn{4}{|l|}{$\mathrm{VC}=$ volume control } \\
\hline \multicolumn{4}{|c|}{ PRVC = pressure-regulated volume control ventilation } \\
\hline \multirow{2}{*}{\multicolumn{4}{|c|}{ APACHE $=$ Acute Physiology and Chronic Health Evaluation }} \\
\hline & & & \\
\hline \multicolumn{4}{|l|}{$\mathrm{IQR}=$ interquartile range } \\
\hline IBW $=$ ideal body weight & & & \\
\hline
\end{tabular}

Baseline TDI was $0.21 \pm 0.06 \mathrm{~cm}$ in the extubation group versus $0.24 \pm 0.07 \mathrm{~cm}$ in the death or tracheostomy group $(P=.053)$. The mean TDI 2 was $0.17 \pm 0.05 \mathrm{~cm}$ in the extubation group versus $0.21 \pm 0.05 \mathrm{~cm}$ in the death or tracheostomy group $(P=.009)$. The change between baseline TDI and TDI 2 was $0.03 \pm 0.03 \mathrm{~cm} / \mathrm{d}$ between measurements in the extubation group versus $0.03 \pm 0.03 \mathrm{~cm} / \mathrm{d}$ between measurements in the death or tracheostomy group $(P=.83)$. The rate of change (thinning) between TDI at baseline and TDI 2 was $0.02 \pm 0.01 \mathrm{~cm} / \mathrm{d}$ between measurements in the extubation group and $0.01 \pm 0.01 \mathrm{~cm} / \mathrm{d}$ between measurements in the death or tracheostomy group $(P=.65$; Table 3$)$.

We found no significant association between the rate of thinning and subject sex $(P=.68)$, diagnosis of COPD $(P=.36)$, current smoking $(P=.85)$, or pleural effusion 
Table 2. Mean Baseline Diaphragm Thickness According to Subjects' Clinical Characteristics

\begin{tabular}{|c|c|c|c|c|c|}
\hline Characteristics & Yes & No & & & $P$ \\
\hline COPD & $0.26 \pm 0.06(13)$ & $0.22 \pm 0.07(66)$ & & & .034 \\
\hline Female & $0.20 \pm 0.06(33)$ & $0.25 \pm 0.06(46)$ & & & .001 \\
\hline Current smoking & $0.22 \pm 0.06(9)$ & $0.23 \pm 0.07(70)$ & & & .90 \\
\hline Pleural effusion & $0.25 \pm 0.07(26)$ & $0.22 \pm 0.06(53)$ & & & .045 \\
\hline Neuromuscular block & $0.31(1)$ & $0.23 \pm 0.07(78)$ & & & NA \\
\hline Corticosteroid use & $0.24 \pm 0.05(10)$ & $0.23 \pm 0.07(69)$ & & & .30 \\
\hline Sepsis/septic shock & $0.22 \pm 0.06(26)$ & $0.23 \pm 0.07(52)$ & & & .70 \\
\hline Malignancy & $0.23 \pm 0.06(9)$ & $0.23 \pm 0.07(70)$ & & & .68 \\
\hline Liver disease & $0.20 \pm 0.04(9)$ & $0.23 \pm 0.07(70)$ & & & .21 \\
\hline Congestive heart failure & $0.26 \pm 0.05(19)$ & $0.22 \pm 0.07(60)$ & & & .003 \\
\hline Coronary artery disease & $0.26 \pm 0.05(19)$ & $0.22 \pm 0.07(60)$ & & & .003 \\
\hline Asthma & $0.20 \pm 0.06(4)$ & $0.23 \pm 0.07(75)$ & & & .38 \\
\hline Neuromuscular disease & $0.21 \pm 0.08(3)$ & $0.23 \pm 0.07(76)$ & & & .76 \\
\hline Connective tissue disease & $0.26 \pm 0.01(2)$ & $0.23 \pm 0.07(77)$ & & & .36 \\
\hline HIV & $0.23 \pm 0.05(8)$ & $0.23 \pm 0.07(71)$ & & & .53 \\
\hline Type of respiratory failure & $\begin{array}{c}\text { Airway protection } \\
0.19 \pm 0.04\end{array}$ & $\begin{array}{c}\text { Hypercapnic } \\
0.20 \pm 0.05 \text { (5) }\end{array}$ & $\begin{array}{c}\text { Hypoxic } \\
0.24 \pm 0.07 \text { (44) }\end{array}$ & $\begin{array}{c}\text { Mixed } \\
0.25 \pm 0.06(15)\end{array}$ & .047 \\
\hline Mode of mechanical ventilation & $\begin{array}{c}\text { APRV } \\
0.22 \pm 0.02 \text { (3) }\end{array}$ & $\begin{array}{c}\text { VC/PRVC } \\
0.23 \pm 0.07(76)\end{array}$ & & & .93 \\
\hline Chest radiography finding & $\begin{array}{l}\text { Diffuse infiltrate } \\
0.23 \pm 0.07 \text { (33) }\end{array}$ & $\begin{array}{c}\text { Lobar/sublobar } \\
0.24 \pm 0.07(21)\end{array}$ & $\begin{array}{c}\text { Normal } \\
0.21 \pm 0.07(25)\end{array}$ & & .31 \\
\hline \multicolumn{6}{|c|}{$\begin{array}{l}\text { Results are mean } \pm \text { SD }(n) \\
\text { APRV }=\text { airway pressure release ventilation } \\
\text { VC }=\text { volume control } \\
\text { PRVC = pressure-regulated volume control ventilation } \\
\text { NA }=\text { not applicable }\end{array}$} \\
\hline
\end{tabular}

$(P=.83)$. Differences in rate of thinning had significance in subjects with congestive heart failure $(P=.048)$ and coronary artery disease $(P=.048$; Table 4$)$. Diaphragm thinning was not associated with age at baseline.

After adjusting for baseline TDI and sex, there was no significant difference in mean change in the diaphragm between the extubated and failed groups $(P=.058)$. In this analysis, the mean change in the extubated group was $0.0116 \mathrm{~cm}$ lower than that in the groups of subjects who died or received a tracheostomy.

\section{Diaphragm Thinning and Extubation Outcome}

Thinner baseline TDI was associated with a higher chance of extubation. For every $0.01-\mathrm{cm}$ decrease in baseline TDI, the hazard (likelihood) of extubation increased by $12.5 \%$ (hazard ratio $0.875,95 \%$ CI $0.801-0.956, P=.003$ ).

A decrease in TDI from baseline to the second diaphragm measurement was also significantly associated with a higher likelihood of extubation. For every $0.01-\mathrm{cm}$ decrease in TDI, the likelihood of extubation increased by $17 \%$ (hazard ratio $0.832,95 \%$ CI $0.697-0.953, P=.041$ ). We performed an additional analysis treating TDI as a time-dependent covariate and found a similar result. In that analysis, a decrease in TDI was significantly associated with a higher chance of extubation. For every $0.01-\mathrm{cm}$ decrease in TDI, the likelihood of extubation increased by $12.1 \%$ (hazard ratio $0.879,95 \%$ CI $0.805-0.960$, $P=.004)$. Figure 2 shows probability without extubation at day 7 and day 15 based on baseline diaphragm thickness and thickness change. Thicker diaphragms were associated with longer time without extubation.

\section{Discussion}

Our results support our hypothesis that patients receiving mechanical ventilation begin to develop diaphragm thinning soon after intubation. Thinning was observed in $84 \%$ of subjects $72 \mathrm{~h}$ after the initiation of mechanical ventilation. Interestingly, however, we found no evidence that the thinning correlates with extubation failure. In fact, the thinner the diaphragm at baseline and the greater the extent of diaphragm thinning at $72 \mathrm{~h}$, the greater the likelihood of extubation.

There are a few possible explanations for these unexpected findings. One explanation is that, in patients who recover faster from their illness, the degree of thinning does not affect the likelihood of extubation; it may be that 
Table 3. Diaphragm Thickness at Baseline, Change of Diaphragm, and the Rate of Thinning Among Subjects Who Were Extubated Versus Those Who Died or Received a Tracheostomy

\begin{tabular}{|c|c|c|c|}
\hline \multirow[b]{2}{*}{ Parameter } & \multicolumn{2}{|c|}{$\begin{array}{c}\text { Diaphragm } \\
\text { Thickness }(\mathrm{cm})\end{array}$} & \multirow[b]{2}{*}{$P$} \\
\hline & $\begin{array}{l}\text { Death or } \\
\text { Tracheostomy } \\
(n=24)\end{array}$ & $\begin{array}{l}\text { Extubated } \\
(n=33)\end{array}$ & \\
\hline TDI baseline & $0.24 \pm 0.07$ & $0.21 \pm 0.06$ & .053 \\
\hline TDI2 & $0.21 \pm 0.05$ & $0.17 \pm 0.05$ & $<.001$ \\
\hline TDI3* & $0.21 \pm 0.04$ & $0.15 \pm 0.02$ & .01 \\
\hline TDI4 $\dagger$ & 0.14 & 0.16 & NA \\
\hline TDI5 $\dagger$ & 0.1 & 0.16 & NA \\
\hline \multicolumn{4}{|l|}{ Diaphragm change $(\mathrm{cm})$} \\
\hline TDI baseline - TDI2 & $0.03 \pm 0.03$ & $0.03 \pm 0.03$ & .83 \\
\hline TDI baseline - last TDI & $0.05 \pm 0.04$ & $0.04 \pm 0.04$ & .48 \\
\hline \multicolumn{4}{|l|}{ Rate of thinning ( $\mathrm{cm}$ change/d) } \\
\hline $\begin{array}{l}\text { TDI baseline }- \text { TDI } 2 / \mathrm{d} \\
\text { between first } 2 \text { TDI } \\
\text { measurements }\end{array}$ & $0.01 \pm 0.01$ & $0.02 \pm 0.01$ & .65 \\
\hline $\begin{array}{l}\text { Results are mean } \pm \text { SD. } \\
* n=8 \text { and } 6 \text { for each group. } \\
\dagger n=1 \text { and } 1 \text { for each group. } \\
\text { TDI }=\text { diaphragm thickness } \\
\text { NA }=\text { not applicable }\end{array}$ & & & \\
\hline
\end{tabular}

mechanical ventilation must last longer than $72 \mathrm{~h}$ to decrease diaphragmatic endurance. Although it is clear that thinning of the diaphragm occurs over time in patients receiving mechanical ventilation, no studies have shown a correlation between the degree of diaphragmatic thinning and diaphragmatic strength; nor have they shown a correlation between diaphragm atrophy and time to extubation. Although the evidence for ventilator-induced diaphragmatic dysfunction in both animal models and human studies is convincing, it is considerably more difficult to prove conclusively that ventilator-induced diaphragm dysfunction correlates with mechanical ventilation weaning. ${ }^{10,11}$ This is due in large part to the presence of multiple confounding factors, such as underlying disease states, drug therapies, and different modes of mechanical ventilation, as well as technical limitations in accurately assessing diaphragmatic function in critically ill patients. Also, as a patient's condition improves, his or her lung compliance and gas exchange improve; diaphragm thinning, even if present, may not have a significant impact on extubation. We could also speculate that that thicker diaphragm may be actually edematous or inflamed muscles due to more severe illness; however, we found no correlation between the thickness and ARDS or multi-organ failure or pressor use.

Another possible explanation for our findings is that muscle injury and dysfunction, well-known phenomena that have a global effect in critical illness, play a major role in extubation failure and that extubation failure cannot be linked solely to diaphragmatic dysfunction. ${ }^{16}$ Levine et al ${ }^{12}$ showed that the combination of diaphragmatic inactivity for $18-96 \mathrm{~h}$ with mechanical ventilation was associated with marked atrophy of both slow-twitch and fasttwitch fibers of the diaphragm. Also, Hooijman et $\mathrm{al}^{4}$ showed that both slow-twitch and fast-twitch diaphragm muscle fibers of critically ill subjects had a smaller crosssectional area (by about 25\%) and a lower contractile force (by $>50 \%$ ) during mechanical ventilation. However, their findings did not provide any evidence of causality, and it remains unclear whether preventing diaphragm atrophy would accelerate liberation from mechanical ventilation. Furthermore, Baldwin et $\mathrm{al}^{17}$ found that respiratory muscle weakness was less marked than peripheral muscle weakness in critically ill subjects. They found that muscle wasting and weakness associated with critical illness were unevenly distributed after extended periods of mechanical ventilation, yet diaphragm strength was relatively well preserved. ${ }^{17}$ A final explanation is that measurements of muscle size in general may not be an appropriate surrogate for strength. It is possible that, during contraction, the diaphragm thickening ratio is a more reliable indicator of diaphragmatic function than diaphragm thinning. Goligher et al ${ }^{18}$ found that changes in diaphragm thickness are common in mechanically ventilated subjects. They found that diaphragm thickness was increased in some subjects and decreased in others, but both groups had significant diaphragm dysfunction, evaluated by thickening ratio.

In this study, we found no correlation between the rate of thinning and the type of respiratory failure, mode of mechanical ventilation, neuromuscular blockade, sepsis, steroid use, or chest radiograph findings. Subjects with congestive heart failure or coronary artery disease had a greater degree of thinning than those without these conditions, but the small size of our sample makes it difficult to draw conclusions from these findings.

Previous studies have shown a high degree of variability in TDI measurements, depending on which intercostal space was used and anatomic position. ${ }^{19}$ To establish the reproducibility of our measurements, we always obtained 3 consecutive images and were careful to perform all of our measurements with the subject sitting upright in bed at a $90^{\circ}$ angle and at the 8th and 9 th intercostal spaces in the right mid-axillary line. A cartoon sketch was kept in each subject's study file depicting the best location for the ultrasound probe placement, allowing us to use the same anatomical measurement position each time. Thus, we believe that our data are reliable. There was no evidence that residual capacity changed significantly over the course of the study, and we were careful to perform all measurements at end 


\section{Diaphragm Muscle Thinning and Extubation}

Table 4. Mean of the Change in Diaphragm Thickness From Baseline to the Last Measurement Divided by the Number of Days Between the 2 Diaphragm Measurements in $\mathrm{cm} \pm \mathrm{SD}$

\begin{tabular}{|c|c|c|c|c|c|}
\hline Characteristics & Yes & No & & & $P$ \\
\hline COPD & $-0.01 \pm 0.01(8)$ & $-0.01 \pm 0.01(49)$ & & & .36 \\
\hline Female & $-0.01 \pm 0.01(24)$ & $-0.01 \pm 0.01(33)$ & & & .68 \\
\hline Current smoking & $-0.01 \pm 0.01(8)$ & $-0.01 \pm 0.01(49)$ & & & .85 \\
\hline Pleural effusion & $-0.01 \pm 0.01(17)$ & $-0.01 \pm 0.01(40)$ & & & .83 \\
\hline Neuromuscular block & $-0.02(1)$ & $-0.01 \pm 0.01(56)$ & & & NA \\
\hline Corticosteroid use & $-0.02 \pm 0.02(6)$ & $-0.01 \pm 0.01(51)$ & & & .32 \\
\hline Sepsis/septic shock & $-0.01 \pm 0.01(20)$ & $-0.01 \pm 0.01(37)$ & & & .72 \\
\hline Malignancy & $-0.01 \pm 0.00(7)$ & $-0.01 \pm 0.01(50)$ & & & .20 \\
\hline Liver disease & $-0.01 \pm 0.01(8)$ & $-0.01 \pm 0.01(49)$ & & & .93 \\
\hline Congestive heart failure & $-0.02 \pm 0.01(14)$ & $-0.01 \pm 0.01$ & & & .048 \\
\hline Coronary artery disease & $-0.02 \pm 0.01(14)$ & $-0.01 \pm 0.01(43)$ & & & .048 \\
\hline Asthma & $-0.01(1)$ & $-0.01 \pm 0.01(56)$ & & & NA \\
\hline Neuromuscular disease & $-0.01 \pm 0.01(3)$ & $-0.01 \pm 0.01(54)$ & & & .97 \\
\hline Connective tissue disease & $-0.00(1)$ & $-0.01 \pm 0.01(56)$ & & & NA \\
\hline HIV & $-0.01 \pm 0.01(6)$ & $-0.01 \pm 0.01(51)$ & & & .98 \\
\hline Type of respiratory failure & $\begin{array}{l}\text { Airway protection } \\
-0.01 \pm 0.01(10)\end{array}$ & $\begin{array}{c}\text { Hypercapnic } \\
0.00 \pm 0.00(2)\end{array}$ & $\begin{array}{c}\text { Hypoxic } \\
-0.01(0.01) ; 34\end{array}$ & $\begin{array}{c}\text { Mixed } \\
-0.01(0.01) ; 11\end{array}$ & .13 \\
\hline Mode of mechanical ventilation & $\begin{array}{c}\text { APRV } \\
-0.01 \pm 0.01(3)\end{array}$ & $\begin{array}{c}\text { VC/PRVC } \\
-0.01 \pm 0.01(54)\end{array}$ & & & .50 \\
\hline Chest radiography finding & $\begin{array}{l}\text { Diffuse infiltrate } \\
-0.01 \pm 0.01(26)\end{array}$ & $\begin{array}{l}\text { Lobar/sublobar } \\
-0.02 \pm 0.01(15)\end{array}$ & $\begin{array}{c}\text { Normal } \\
-0.01(0.01) ; 16\end{array}$ & & .20 \\
\hline \multicolumn{6}{|c|}{$\begin{array}{l}\text { Results are mean } \pm \mathrm{SD}(n) \\
\mathrm{NA}=\text { not applicable } \\
\text { APRV }=\text { airway pressure release ventilation } \\
\mathrm{VC}=\text { volume control } \\
\text { PRVC }=\text { pressure-regulated volume control ventilation }\end{array}$} \\
\hline
\end{tabular}
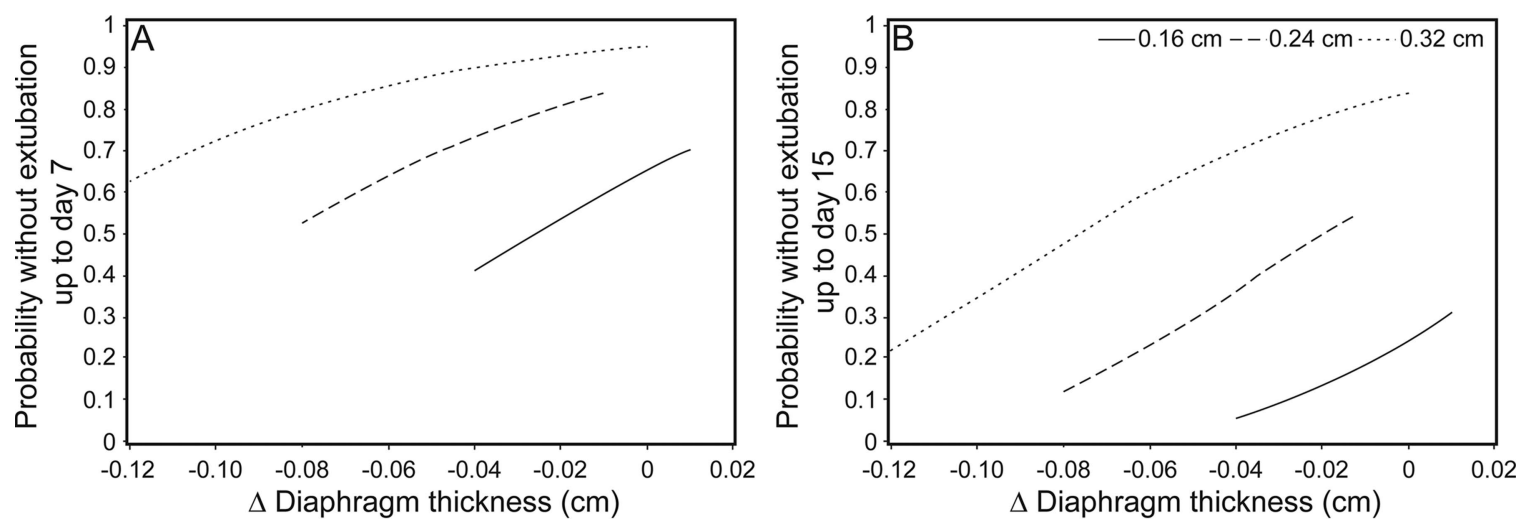

Fig. 2. Probability without extubation at day 7 (A) and day 15 (B) based on baseline diaphragm thickness $(0.16,0.24$, and $0.32 \mathrm{~cm})$ and thickness change. Thicker diaphragms were associated with longer time without extubation.

expiration to minimize hyperinflation as a confounding variable. Nevertheless, the effect of increased lung volumes thickens the diaphragm and does not thin it. ${ }^{17} \mathrm{On}$ the other hand, if the patient's lung volume fell substantially we would expect a decrease in thickness as we observed. ${ }^{17}$ None of our subjects had a significant volume loss as observed by chest radiograph. However, other potential confounding variables, such as nutri- tional status and abdominal and thoracic musculature, were not evaluated. ${ }^{17,20}$

The average baseline TDI in our subjects was $0.23 \pm 0.06 \mathrm{~cm}$, but normal values for TDI have not been precisely determined. ${ }^{15,21}$ Like Boon et al, ${ }^{19}$ we found no correlation between body mass index and baseline TDI. On the other hand, as has been reported elsewhere, females had significantly thinner diaphragms than males..22,23 


\section{Diaphragm Muscle Thinning and Extubation}

A limitation of this study is that the sample size is small, and the study is underpowered to conclude whether the observed thinning correlates with diaphragm strength. We did not evaluate thickening ratio, which may be a more reliable measurement of diaphragmatic function. Another limitation is that we did not perform measurements immediately before extubation as well as after extubation or tracheostomy; thus, we do not know in what direction those measurements may have changed. Also, sitting our subjects up was easy but required 2 operators; therefore, the test was done very quickly, in approximately $4-5 \mathrm{~min}$. However, one of the weaknesses of our method is that we only obtained one measurement/d for each subject, and we did not establish reproducibility of the measurement.

\section{Conclusions}

Although most of the subjects in this study showed evidence of progressive diaphragm thinning on serial ultrasound measurements, we were unable to find a correlation with extubation failure. Future well-powered studies should be designed to investigate which factors are associated with diaphragm muscle strength in mechanically ventilated patients.

\section{REFERENCES}

1. Esteban A, Anzueto A, Alía I, Gordo F, Apezteguía C, Pálizas F, et al. How is mechanical ventilation employed in the intensive care unit? An international utilization review. Am J Respir Crit Care Med 2000;161(5):1450-1458.

2. Esteban A, Alia I, Ibañez J, Benito S, Tobin MJ. Modes of mechanical ventilation and weaning: a national survey of Spanish hospitals: the Spanish Lung Failure Collaborative Group. Chest 1994;106(4): 1188-1193.

3. Esteban A, Frutos F, Tobin MJ, Alía I, Solsona JF, Valverdú I, et al. A comparison of four methods of weaning patients from mechanical ventilation: Spanish Lung Failure Collaborative Group. N Engl J Med 1995;332(6):345-350.

4. Hooijman PE, Beishuizen A, Witt CC, de Waard MC, Girbes AR, Spoelstra-de Man AM, et al. Diaphragm muscle fiber weakness and ubiquitin-proteasome activation in critically ill patients. Am J Respir Crit Care Med 2015;191(10):1126-1138.

5. van der Schaaf M, Dettling DS, Beelen A, Lucas C, Dongelmans DA, Nollet F. Poor functional status immediately after discharge from an intensive care unit. Disability and rehabilitation 2008;30(23): 1812-1818.

6. Herridge MS, Cheung AM, Tansey CM, Matte-Martyn A, DiazGranados N, Al-Saidi F, et al. One-year outcomes in survivors of the acute respiratory distress syndrome. N Engl J Med 2003;348(8):683693.
7. Azuelos I, Jung B, Picard M, Liang F, Li T, Lemaire C, et al. Relationship between autophagy and ventilator-induced diaphragmatic dysfunction. Anesthesiology 2015;122(6):1349-1361.

8. Picard M, Azuelos I, Jung B, Giordano C, Matecki S, Hussain S, et al. Mechanical ventilation triggers abnormal mitochondrial dynamics and morphology in the diaphragm. J Appl Physiol 2015;118(9): 1161-1171.

9. Valenzuela VJ, Pinochet UR, Escobar CM, Márquez AJ, Riquelme VR, Cruces RP. [Ventilator-induced diaphragmatic dysfunction]. Rev Chil Pediatr 2014;85(4):491-498.

10. Sassoon CS, Zhu E, Caiozzo VJ. Assist-control mechanical ventilation attenuates ventilator-induced diaphragmatic dysfunction. Am J Respir Crit Care Med 2004;170(6):626-632.

11. Vassilakopoulos T, Petrof BJ. Ventilator-induced diaphragmatic dysfunction. Am J Respir Crit Care Med 2004;169(3):336-341.

12. Levine S, Nguyen T, Taylor N, Friscia ME, Budak MT, Rothenberg $\mathrm{P}$, et al. Rapid disuse atrophy of diaphragm fibers in mechanically ventilated humans. N Engl J Med 2008;358(13):1327-1335.

13. Betters JL, Criswell DS, Shanely RA, Van Gammeren D, Falk D, Deruisseau KC, et al. Trolox attenuates mechanical ventilation-induced diaphragmatic dysfunction and proteolysis. Am J Respir Crit Care Med 2004;170(11):1179-1184.

14. Grosu HB, Lee YI, Lee J, Eden E, Eikermann M, Rose KM. Diaphragm muscle thinning in patients who are mechanically ventilated. Chest 2012;142(6):1455-1460.

15. Cohn D, Benditt JO, Eveloff S, McCool FD. Diaphragm thickening during inspiration. J Appl Physiol 1997;83(1):291-296.

16. Pati S, Goodfellow JA, Iyadurai S, Hilton-Jones D. Approach to critical illness polyneuropathy and myopathy. Postgrad Med J 2008; 84(993):354-360.

17. Baldwin CE, Paratz JD, Bersten AD. Diaphragm and peripheral muscle thickness on ultrasound: intra-rater reliability and variability of a methodology using non-standard recumbent positions. Respirology 2011;16(7):1136-1143.

18. Goligher EC, Fan E, Herridge MS, Murray A, Vorona S, Brace D, et al. Evolution of diaphragm thickness during mechanical ventilation: impact of inspiratory effort. Am J Respir Crit Care Med 2015;192(9): 1080-1088.

19. Boon AJ, Harper CJ, Ghahfarokhi LS, Strommen JA, Watson JC, Sorenson EJ. Two-dimensional ultrasound imaging of the diaphragm: quantitative values in normal subjects. Muscle Nerve 2013;47(6): 884-889.

20. Arora NS, Rochester DF. Effect of body weight and muscularity on human diaphragm muscle mass, thickness, and area. J Appl Physiol Respir Environ Exerc Physiol 1982;52(1):64-70.

21. Wait JL, Nahormek PA, Yost WT, Rochester DP. Diaphragmatic thickness-lung volume relationship in vivo. J Appl Physiol 1989; 67(4): 1560-1568

22. Harper CJ, Shahgholi L, Cieslak K, Hellyer NJ, Strommen JA, Boon AJ. Variability in diaphragm motion during normal breathing, assessed with B-mode ultrasound. J Orthop Sports Phys Ther 2013; 43(12):927-931.

23. Caskey CI, Zerhouni EA, Fishman EK, Rahmouni AD. Aging of the diaphragm: a CT study. Radiology 1989;171(2):385-389. 